\title{
Hepatitis B surface antigen carrier rate in unvaccinated and vaccinated children with thalassaemia major at Bahawal Victoria Hospital, Bahawalpur, Pakistan
}

\author{
A. Rehman, ${ }^{1}$ A. Mazhar, ${ }^{1}$ M.A. Sheikh, ${ }^{1}$ M.M. Naeem ${ }^{2}$ and I.A. Bhatti
}

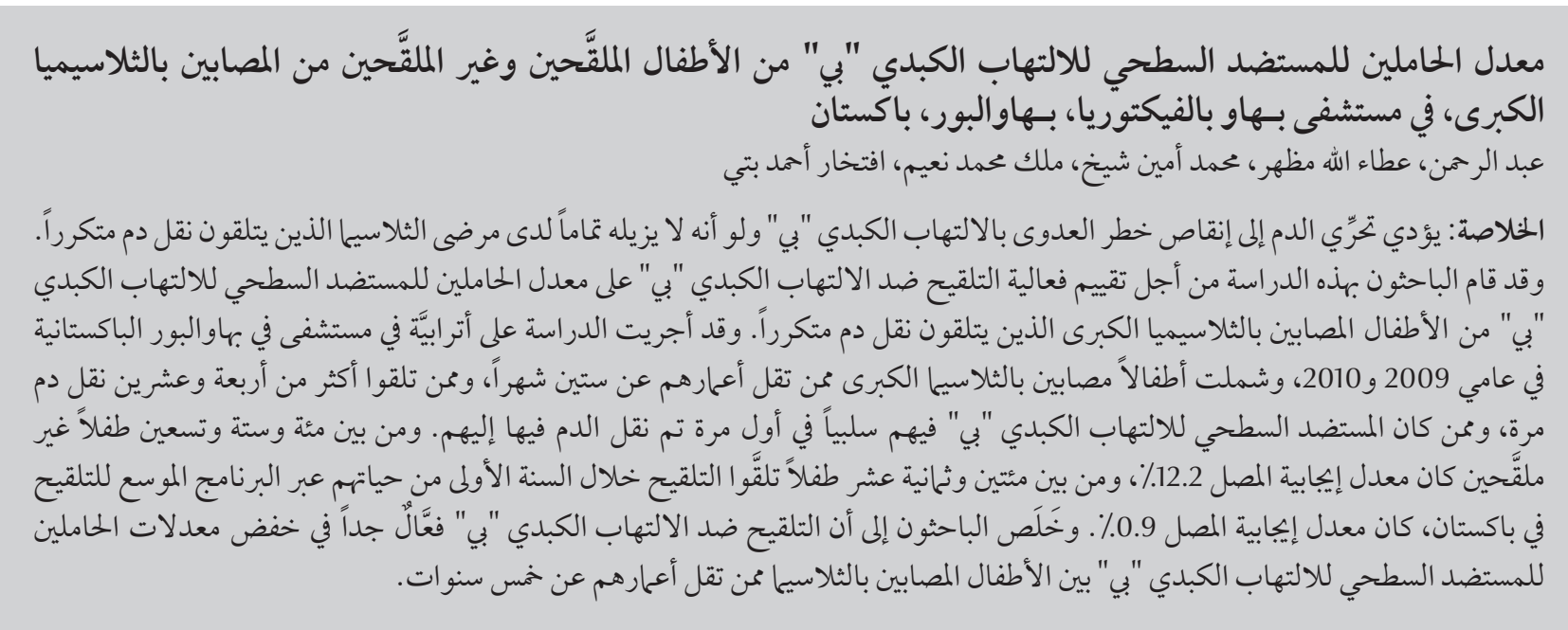

ABSTRACT Screening of blood reduces but does not eliminate the risk of hepatitis B virus (HBV) infection in multitransfused thalassaemia patients. This study was done to evaluate efficacy of HBV vaccination on hepatitis B virus surface antigen ( $\mathrm{HBsAg}$ ) carrier rate in children with thalassaemia major receiving multiple blood transfusions. In a cohort study conducted at a hospital in Bahawalpur, Pakistan, during 2009-10, children with thalassaemia major aged $<60$ months who received more than 24 blood transfusions and were HBsAg negative at the time of first blood transfusion were included. Of 196 unvaccinated children, the seropositive rate was $12.2 \%$; while among 218 children vaccinated during the first year of life via the Pakistan Expanded Programme on Immunization, the seropositive rate was only $0.9 \%$. The HBV vaccine was highly effective in reducing the HBsAg carrier rate in children with thalassaemia aged $<5$ years.

Taux de porteurs de l'antigène de surface de l'hépatite B chez des enfants non vaccinés et vaccinés atteints de thalassémie majeure à I'hôpital Bahawal Victoria de Bahawalpur (Pakistan)

RÉSUMÉ Le dépistage du sang réduit le risque d'une infection par le virus de l'hépatite B chez les patients multitransfusés atteints de thalassémie, mais ne l'élimine pas. La présente étude a été menée pour évaluer l'efficacité de la vaccination contre le virus de l'hépatite B sur le taux de porteurs de l'antigène de surface de l'hépatite B chez des enfants atteints de thalassémie majeure et recevant de multiples transfusions. Des enfants souffrant de thalassémie majeure, âgés de moins de 60 mois, ayant reçu plus de 24 transfusions sanguines et qui étaient négatifs pour l'antigène de surface du virus de l'hépatite B au moment de la première transfusion ont été inclus dans une étude de cohorte réalisée dans un hôpital de Bahawalpur (Pakistan) en 2009 et 2010. Sur 196 enfants non vaccinés, le taux de séropositivité était de 12,2 \%, alors que sur 218 enfants vaccinés au cours de leur première année de vie dans le cadre du programme élargi de vaccination au Pakistan, le taux de séropositivité était de seulement $0,9 \%$. Le vaccin contre le virus de l'hépatite B a été très efficace pour réduire le taux de porteurs de l'antigène de surface du virus de l'hépatite B chez les enfants de moins de cinq ans atteints de thalassémie. 


\section{Introduction}

Thalassaemia is an hereditary anaemia which requires lifelong blood transfusions. Hepatitis B virus (HBV) infection is one of the most common transfusiontransmitted infections. The prevalence of HBV in children with thalassaemia receiving multiple blood transfusions had been recorded as high as 20\% [1]. Screening of blood for hepatitis $B$ virus surface antigen (HBsAg) reduces but does not eliminate the risk of $\mathrm{HBV}$ infection, probably due to the "window period", low HBV titres or infection with HBV variants [2]. Luckily, the available vaccine against $\mathrm{HBV}$ is highly effective even when given during infancy [3]. A study conducted in Alexandria, Egypt showed that the HBsAg carrier rate among children who had been vaccinated against $\mathrm{HBV}$ in the first year of life was $0.8 \%$ compared with $2.2 \%$ among non-vaccinated children, when tested at aged 6 years of life [4]. Another study in a rural community in mid-western Nigeria showed that the rate of HBsAg positivity among vaccinated children was $1.3 \%$ compared with $4.6 \%$ among non-vaccinated children [5]. A study in Tanzania showed that $1.7 \%$ of healthy children under 5 years vaccinated at 4 , 8 and 12 weeks of life were positive for HBsAg [6].

A number of immunological defects have been described in thalassaemia major [7] as well as iron overload, which may also lead to an immunodeficiency condition [8]. The effect of these defects on vaccine response is controversial $[9,10]$. The purpose of this study was to determine whether $\mathrm{HBV}$ vaccination was effective in reducing the $\mathrm{HBsAg}$ carrier rate in children with thalassaemia major.

\section{Methods}

This cohort study was conducted in the thalassaemia centre attached to the Paediatric Unit-I of Bahawal Victoria Hospital, Bahawalpur, Pakistan, during
April 2009 to April 2010. The study was approved by the ethics committee of the institution. Verbal consent was taken from the parents before inclusion of the children in the study.

\section{Sample}

The sample size was calculated by taking the anticipated probability of infection among thalassaemic children as 0.2 and anticipated probability of infection among children in the general population as 0.05 , level of precision $50 \%$ and confidence interval $95 \%$. The minimum sample required was 184 [11].

The vaccinated cohort were children with thalassaemia major, aged < 60 months, on regular follow up, who had received more than 24 blood transfusions, were vaccinated against HBV and were HBsAg negative at the time of first blood transfusion. Vaccination was done during infancy via the Pakistan Expanded Programme on Immunization (EPI) and was by recombinant DNA HBV vaccine in a dose of $10 \mu \mathrm{g}$, in a combined vaccine with diphtheria, tetanus and pertussis, on a monthly basis for 3 doses. Children who received a blood transfusion before completion of vaccination (3 doses of $\mathrm{HBV}$ vaccine), children who received more than 3 doses of HBV vaccine or children with incomplete data were excluded from the study.

For comparison the control cohort were children with thalassaemia major who were unvaccinated against HBV, who underwent HBsAg screening before later $\mathrm{HBV}$ vaccination during January 2002 to December 2004, were aged $<60$ months at the time of screening, had received more than 24 blood transfusions and were HBsAg antigen negative at the time of first blood transfusion. Children with incomplete data were excluded.

\section{Data collection}

Data on the children's background characteristics and immunization status were extracted from the children's records. A second generation enzyme-linked immunosorbent assay method was used to detect HBsAg using a standard kit with the manufacturer's recommended methods and cut-offs (Axim HBsAg, Abbott Laboratories). All the children received blood after screening for HBV through the blood bank of Bahawal Victoria hospital.

\section{Data analysis}

The analysis of the data was done by the statistical programs Standard Deviation Calculator (http://www.easycalculation.com/statistics/standard-deviation. php) and GraphPad (http://www. graphpad.com/quickcalcs/index.cfm). Fisher exact test for categorical data and $t$-test for continuous data were used to analyse the data and $P$-value $<0.05$ was taken as significant.

\section{Results}

There were 196 children in the unvaccinated cohort and 218 in the vaccinated cohort. There were no significant differences between the 2 cohorts in terms of sex distribution, mean age and mean number of blood transfusions (Table 1).

There were 24 children positive for HBsAg in the unvaccinated cohort, giving a seropositive rate of $12.2 \%$, while 2 children were positive for HBsAg in the vaccinated cohort, a positivity rate of $0.9 \%(P<0.001)$.

Among the 2 vaccinated children who were $\mathrm{HBs} A g$ positive, one was a 31-month-old girl who had received 25 blood transfusions and whose mother was also HBsAg positive, while the other was a 59-month-old boy who had received 50 blood transfusions. Both were negative for HBV DNA.

\section{Discussion}

This study was conducted to establish the effectiveness of $\mathrm{HBV}$ vaccination given through the EPI in reducing the 


\begin{tabular}{|c|c|c|c|}
\hline Characteristic & $\begin{array}{l}\text { Vaccinated cohort } \\
\qquad(n=218)\end{array}$ & $\begin{array}{l}\text { Unvaccinated cohort } \\
\qquad(n=196)\end{array}$ & $P$-value \\
\hline$\%$ of girls & 69 & 44 & 0.156 \\
\hline Mean (SD) age (months) & $44.4(8.6)$ & $42.9(8.4)$ & 0.156 \\
\hline Mean (SD) blood transfusions (no.) & $35.1(8.6)$ & $33.6(8.2)$ & 0.064 \\
\hline
\end{tabular}

$S D=$ standard deviation .

HBsAg carrier rate in thalassaemic children aged $<5$ years receiving multiple blood transfusions. HBV vaccination starts at a minimum of 6 weeks of age through the EPI in Pakistan. The HBsAg carrier rate in the Pakistani paediatric population is $2.4 \%$ [12]. In our study the HBsAg carrier rate was $12.2 \%$ in the unvaccinated cohort compared with the significantly lower rate of $0.9 \%$ in the vaccinated cohort. The study shows that vaccination in the first year of life was highly effective in reducing the HBsAg carrier rate in thalassaemic children receiving multiple blood transfusions.

Mirmomen et al. from the Islamic Republic of Iran showed that $1.5 \%$ of thalassaemic children who received multiple blood transfusions were HBsAg positive and $76.0 \%$ of these patients were fully vaccinated against $\mathrm{HBV}$ [13]. This HBsAg carrier rate was nearly equal to or even lower than the value reported from the general Iranian population $(2.5 \%-3.5 \%)$ [14]. Al-Fawaz et al. reported that none of 5 vaccinated Saudi children with thalassaemia major aged 1-14 years were positive for $\mathrm{HBs} A g$ [15]. Mokhles et al. studied the HBsAg carrier rate in 10-16-year-old high-risk children having multiple blood transfusions (52\% of 48 children were thalassaemic) and in controls [16]. Both groups were vaccinated by 3 -dose series at 0,1 and 6 months during infancy and the seropositive rate was $31.3 \%$ in the high-risk and $18.8 \%$ in the control group.

Jaiswal et al. showed that none of the 40 children in the age group 0-5 years were positive for $\mathrm{HBsAg}$, while $3 / 39(7.7 \%)$ in the age group $5-10$ years were positive for HBsAg and $1 / 25$ (4.0\%) were positive in the age group 10-15 years [17]. Sharifi et al. noted that $0 / 27$ children aged $1-5$ years and $1 / 59$ children aged $6-10$ years (vaccinated at 0,1 and 6 months of age) were positive for HBsAg [18]. Singh et al. studied thalassaemic vaccinated children and found the rate of HBsAg positivity was $32.1 \%$ in vaccine responders and $35.3 \%$ in non-responders, a difference that was not significant [19]. A number of mutations were observed in the HBV $S$ gene and the authors suggested that the reason for the high frequency of $\mathrm{HBV}$ infection in vaccine responders and non-responders was the presence of these HBV mutants. HBV mutants capable of escaping vaccination have been identified in immunized children worldwide [20].

The reason for the increasing rate of HBsAg with increasing age reported in certain studies $[17,18]$ may be due to infection with $\mathrm{HBV}$ mutants or waning of immunity with age. Further studies are needed to address this issue.

\section{Conclusion}

HBV vaccine was highly effective in reducing the HBsAg carrier rate in children with thalassaemia under the age of 5 years who were vaccinated with $\mathrm{HBV}$ vaccine through the Pakistan EPI.

\section{References}

1. Irshad M, Peter S. Spectrum of viral hepatitis in thalassemic children receiving multiple blood transfusions. Indian Journal of Gastroenterology, 2002, 21:183-184.

2. Rasenack JWF, Schlayer H, Hettler F. Hepatitis B virus infection without immunological markers after open-heart surgery. Lancet, 1995, 345:355-357.

3. Mackie $\mathrm{CO}$ et al. Hepatitis B immunization strategies: timing is everything. Canadian Medical Association Journal, 2009, 180:196-202.

4. Reda AA et al. Epidemiologic evaluation of the immunity against hepatitis B in Alexandria, Egypt. European Journal of Epidemiology, 2003, 18:1007-1011.

5. Odusanya OO et al. Prevalence of hepatitis B surface antigen in vaccinated children and controls in rural Nigeria. International Journal of Infectious Diseases, 2005, 9:139-143.

6. Metodi J et al. Immunity to hepatitis B vaccine in Tanzanian under-5 children. Annals of Tropical Paediatrics, 2010, 30:129-136.
7. Ricerca BM, Girolamo AD, Rund D. Infection in thalassemia and hemoglobinopathies: focus on therapy-related complications. Mediterranean Journal of Hematology and Infectious Diseases, 2009, 1(1) (http://www.mjhid.org/article/view/5229/ e2009028, accessed 6 March 2012).

8. Shaiegan $\mathrm{M}$ et al. Comparison of neutrophile function in patients with thalassemia major and healthy controls. Archives of Iranian Medicine, 2002, 5:175-178.

9. Azarkeivan A et al. Antibody titration and immune response of Iranian beta-thalassemic patients to hepatitis B virus vaccine (booster effect). Pediatric Hematology and Oncology, 2009, 26:195-201.

10. Froutan-Pishbijari $\mathrm{H}$ et al. Immunogenicity of hepatitis B vaccine in multi-transfused thalassemic patients with and without hepatitis C infection: a comparative study with healthy controls. Medical Science Monitor, 2004, 10:CR679CR683. 
11. Lwanga SK, Lemeshow S. Sample size determination in health studies: a practical manual. Geneva, World Health Organization, 1991.

12. Ali SA et al. Hepatitis B and hepatitis C in Pakistan: prevalence and risk factors. International Journal of Infectious Diseases, 2009, 13:9-19.

13. Mirmomen S et al. Epidemiology of hepatitis B, hepatitis C, and human immunodeficiency virus infections in patients with beta-thalassemia in Iran: a multicenter study. Archives of Iranian Medicine, 2006, 9:319-323.

14. Zali MR. Epidemiology of hepatitis B in the Islamic Republic of Iran. Eastern Mediterranean Health Journal, 1998, 2:290-297.

15. Al-Fawaz I, Ramia S. Decline in hepatitis B infection in sickle cell anaemia and beta thalassaemia major. Archives of Disease in Childhood, 1993, 69:594-596.
16. Mokhles $M$ et al. Long term efficacy of hepatitis B vaccine among high risk multiple blood transfusion children in Egypt. International Journal of Infection Control, 2010, 6(2) (http:// www.ijic.info/article/view/5364, accessed 6 March 2012).

17. Jaiswal SP et al. Prevalence of hepatitis viruses among multitransfused homogenous thalassaemia patients. Hepatology Research, 2001, 19:247-253.

18. Sharifi Z, Milani S, Shooshtari MS. Study on efficacy of hepatitis $B$ immunization in vaccinated beta-thalassemia children in Tehran. Iranian Journal of Pediatrics, 2010, 20:211-215.

19. Singh $\mathrm{H}$ et al. High frequency of hepatitis B virus infection in patients with beta-thalassemia receiving multiple transfusions. Vox Sanguinis, 2003, 84:292-299.

20. Madalinski K. Recent advances in hepatitis B vaccination. Hepatitis B Annual, 2008, 5:51-65.

\section{WHO position on hepatitis B vaccine}

All infants should receive their first dose of hepatitis B vaccine as soon as possible after birth, preferably within 24 hours. In countries where there is high disease endemicity and where $\mathrm{HBV}$ is mainly spread from mother to infant at birth or from child to child during early childhood, providing the first dose at birth is particularly important, but even in countries where there is intermediate endemicity or low endemicity an important proportion of chronic infections are acquired through early transmission.

Delivery of hepatitis B vaccine within 24 hours of birth should be a performance indicator for all immunization programmes, and reporting and monitoring systems should be strengthened to improve the quality of data on the birth dose. National strategies to prevent perinatal transmission should include providing hepatitis B vaccine at birth and ensuring high coverage of the birth dose through a combination of strengthened maternal and infant care at birth with skilled health workers present to administer the vaccine and innovative outreach to provide vaccine for children born at home.

Source: Hepatitis B vaccines: WHO position paper. Weekly epidemiological record, 2009, 84:405-420 